\title{
Introduction to the Digital Services and Digitalization of Services Minitrack
}

\author{
Tilo Böhmann \\ Universität Hamburg \\ tilo.boehmann@uni-hamburg.de
}

\author{
Jan Marco Leimeister \\ University of St. Gallen \\ janmarco.leimeister@unisg.ch
}

\author{
Tuure Tuunanen \\ University of Jyväskylä \\ tuure@tuunanen.fi
}

This minitrack deals with the innovation, design, development, management, and use of digital services and the digitalization of services. The key drivers in this area of research are the multiplying technological opportunities for digital services, such as ubiquitous connectivity, wearable devices, cyber-physical systems, Internet of Things (IoT), natural language assistants, virtual/augmented reality, cognitive computing, and so on. The minitrack provides a discussion forum for researchers interested theoretical and practical problems related to such services [1,2].

In a broad sense, digital services can be defined as systems that enable value co-creation and limit value co-destruction through the development and implementation of ICT enabled processes that integrate system value propositions with customer value drivers $[3,4]$. Such services meld the worlds of bits and atoms and promise to transform the transportation, energy, and other sectors like the media industries before them. They draw on different technologies such as sensors, real-time analytics of data, augmented and virtual realities, computer hardware, software, and human and system actors. Such technologies form a service platform where different actors [5] assemble the service together, in situ. As a result, the embedded systems of today and the Internet-of-things of tomorrow are the precursors for the upcoming era of cyber physical services (CPS). Examples of such services are, e.g., biomedical and healthcare systems such as telerobotic surgery, (semi)autonomous vehicles and intelligent highways, augmented human capabilities with body net sensors and virtual reality, and intelligent machines.

Furthermore, there are substantial opportunities for ICT and digitalization driven service innovation in industrial and business-to-business settings. These opportunities exist particularly in manufacturing in which innovation activities increase the digitization of products and production processes. We see that the global awareness of the power of the manufacturing industry will be linked to horizontal cyberphysical systems that enable value co-creation and co-destruction in the networked business environment. The cyber-aspects of such systems are ICT infrastructure, computer hardware, software, and different kind of sensors and actors. These components turn cyber-physical systems into platforms for designing and operating service. The data on products and processes gained through networked CPS and the ability to act on this data through control systems and actors enables novel ways of co-creating service in industrial contexts.

This year we received fourteen submissions, of which six were accepted to the minitrack with an acceptance rate of ca. $42 \%$. These are similar to last year's statistics. The papers included in this year's minitrack cover topics of value co-creation and co-destruction, cyber physical services with mobile robotics, smart home ecosystems and consumers, data driven service innovation, and sematic shopping. In addition, we received a paper about conceptualization of digital services and service digitalization.

The articles are summarized in below:

"Actors' Dynamic Value Co-creation and Codestruction Behavior in Service Systems: A Structured Literature Review" by Mengcheng Li and Tuure Tuunanen:

- The paper investigates resource integration and social interaction as the two core processes of value co-creation and codestruction in a service system. Researchers apply a structured literature review as a research methodology to develop a framework to depict the components of value co-creation and co-destruction processes and to understand the behavioral drivers of service system actors as well as the positive and negative value outcomes derived through resource integration and social interaction.

"An Experimental Case Study on Edge Computing based Cyber-Physical Digital Service Provisioning with Mobile Robotics" by James Spohrer, Pekka Pääkkönen, Jani Koivusaari, and Daniel Pakkala: 
- This paper argues that digitalization of physical interaction and infrastructure intensive industries provide an opportunity for new kind of value co-creation via cyberphysical digital service provisioning. The paper explores concept of cyber-physical digital service and presents an experimental case study on cyber-physical digital service provisioning for building diagnostics, utilizing a mobile robot as service actor and resource.

'Take it Personally - The Role of Consumers' Perceived Value of Personalization on CrossCategory Use in a Smart Home Ecosystem" by Børge Obel, Christian Brock, Andrea Carugati, and Marco Hubert:

- The paper argues that a smart home ecosystem generates value for both companies and customers, but due complexity of the ecosystem, which is based on data sharing and personalization it also generates tensions between the value created by data sharing and the value of privacy. The results show that especially consumers' perceived value from personalization plays a significant role in smart home ecosystem acceptance.

"The roles of individual actors in data-driven service innovation - A dynamic capabilities perspective to explore its microfoundations" by Julia M. Jonas and Martin Schymanietz:

- The paper looks at the increasing amount of data that can be collected from interconnected devices offers various opportunities for the co-creative innovation of data-driven services. The study takes a microfoundational view and investigates the roles of individual actors that together shape an organization's ability to innovate. By identifying relevant activities and their relative importance in the innovation of data-driven services, the paper specifies nine actor roles and their contribution to organizational capabilities.

"Semantic Shopping: A Literature Study" by Michael Rosemann, Jörg Becker, Ann-Kristin Cordes, and Benjamin Barann:

- The paper argues that digitalization of the economy and society overall has a significant impact on customers' shopping behavior. What's more, after being conditioned by experiences in entertainment or simple Internet search, customers increasingly expect that a smart shopping assistant understands his/her shopping intentions and transfers these to shopping recommendations. Thus, the emerging opportunity in this context is to facilitate an intention-based shopping experience similar to the way semantic search engines provide responses to enquiries. The paper differentiates alternative types of shopping intentions to provide the first set of conversation patterns and defines semantic shopping and different types of shopping intentions are deduced.

"How Well Do Service Concepts Apply to Digital Services and Service Digitalization?" by Steven Alter:

- This paper explores the extent to which typical service concepts apply to digital service and service digitalization. It defines service, service systems, digital, digitalization, digital objects, digital agents, digital service, and service digitalization. These definitions are applied to four real world cases.

This is our $10^{\text {th }}$ mini track on the topic of digital services. Next year, we again look forward to receive your submissions!

\section{References}

[1] R. F. Lusch and S. Nambisan, "Service Innovation: A Service-Dominant Logic Perspective," Mis Quarterly, vol. 39, pp. 155175, 2015.

[2] C. Peters, P. Maglio, R. Badinelli, R. R. Harmon, R. Maull, J. C. Spohrer, et al., "Emerging digital frontiers for service innovation," Communications of the Association for Information Systems, vol. 39, 2016.

[3] J. Lintula, T. Tuunanen, and M. Salo, "Conceptualizing the Value Co-Destruction Process for Service Systems: Literature Review and Synthesis," in Proceedings of the 50th Hawaii International Conference on System Sciences, 2017.

[4] T. Tuunanen, M. Myers, and H. Cassab, "A Conceptual Framework for Consumer Information Systems Development," Pacific Asia Journal of the Association for Information Systems, vol. 2, pp. 47-66, 2010.

[5] K. Storbacka, R. J. Brodie, T. Böhmann, P. P. Maglio, and S. Nenonen, "Actor engagement as a microfoundation for value co-creation," Journal of Business Research, vol. 69, pp. 3008-3017, 2016. 